\title{
Maternal High-Fat Diet Programs for Metabolic Disturbances in Offspring despite Leptin Sensitivity
}

\author{
Ana Maria Volpato Alini Schultz Eduardo Magalhães-da-Costa \\ Marcelo Lima de Gusmão Correia Márcia Barbosa Águila \\ Carlos Alberto Mandarim-de-Lacerda
}

Laboratory of Morphometry, Biomedical Center, Institute of Biology, State University of Rio de Janeiro, Rio de Janeiro, Brazil

\section{Key Words}

Fetal programming, obesity $\cdot$ Leptin resistance

\section{Abstract}

A fatty diet during pregnancy in mouse dams causes metabolic abnormalities (similar to metabolic syndrome in humans) in the rodents' offspring. We tested the hypothesis that the offspring of dams fed a high-fat diet during pregnancy and lactation develop metabolic abnormalities and leptin resistance. Pregnant C57BL/6 mice $(n=20)$ were fed either standard chow (SC; 19\% fat) or a high-fat diet (HF; $49 \%$ fat). After weaning, male offspring were divided into four groups, according to the diet of dams and offspring: $\mathrm{SC}$ (dams)/SC(offspring), SC/HF, HF/SC and HF/HF ( $\mathrm{n}=30$ / group). For a metabolic analysis, we evaluated body mass, fat mass depots, blood plasma and adipocyte structure at 12 weeks of age. To analyse leptin sensitivity, each group was divided into two groups (vehicle or leptin) to identify the feeding response and DSTAT3 expression after acute intracerebroventricular (ICV) treatment. The offspring of mothers fed a high-fat diet presented increased body mass and visceral fat, adipocyte hypertrophy and insulin resistance. This phenotype was not associated with central leptin resistance. Thus, maternal programming by HF predisposes offspring to metabolic abnormalities despite leptin sensitivity.

Copyright $\odot 2012$ S. Karger AG, Basel

\section{Introduction}

Maternal feeding patterns during pregnancy and the ensuing fetal and neonatal nutrition status may cause developmental adaptations that permanently change the physiology and metabolism in the offspring of humans and experimental animals, potentially predisposing them to cardiovascular, metabolic and endocrine diseases in adult life [1-3]. This phenomenon is called programming and could be associated with epigenetic changes during early life [4].

Experimental studies have shown that maternal highfat diet (HF) consumption during pregnancy predisposes the offspring to obesity and glucose intolerance in adult life $[5,6]$. A HF during pregnancy and lactation also increases plasma glucose and triglyceride levels, body mass and adiposity and causes liver steatosis in the offspring [7].

\section{KARGER}

Fax +41613061234

E-Mail karger@karger.ch

www.karger.com
(C) 2012 S. Karger AG, Basel

0028-3835/12/0964-0272\$38.00/0

Accessible online at:

www.karger.com/nen
Carlos Alberto Mandarim-de-Lacerda

Laboratório de Morfometria, Metabolismo e Doença Cardiovascular

Centro Biomedico, Instituto de Biologia, Universidade do Estado do Rio de Janeiro

Av. 28 de Setembro 87 (fds), Rio de Janeiro, RJ 20551-030 (Brasil)

Tel. +55 212868 8316, E-Mail mandarim@uerj.br 
Table 1. Experimental diets

\begin{tabular}{lrr}
\hline Nutrients, g/kg & \multicolumn{2}{c}{ Diet } \\
\cline { 2 - 3 } & SC & HF \\
\hline Casein (85\% of protein) & 190 & 230 \\
Corn starch & 539.5 & 299.5 \\
Sucrose & 100 & 100 \\
Soybean oil & 70 & 70 \\
Lard & - & 200 \\
Fiber & 50 & 50 \\
Vitamin mixture, mg & 10 & 10 \\
Mineral mixture, mg & 35 & 35 \\
Cysteine & 3 & 3 \\
Choline & 2.5 & 2.5 \\
Antioxidants & 0.014 & 0.014 \\
Total mass, g & 1,000 & 1,000 \\
Energy, kcal/kg & 3,950 & 4,950 \\
Carbohydrates, \% & 64 & 32 \\
Proteins, \% & 19 & 19 \\
Lipids, \% & 17 & 49 \\
\hline
\end{tabular}

Vitamin and mineral mixtures follow the American Institute of Nutrition AIN-93G recommendation for rodents.

Several mechanisms could explain the obesogenic effects mediated by maternal nutrition during pregnancy and lactation in rodents, including the modulation of peptides with hypothalamic action involved in the regulation of food intake and metabolic rate, such as leptin [8-11].

Leptin is secreted by adipocytes and regulates appetite and energy expenditure in humans and rodents, acting on $\mathrm{Ob}-\mathrm{Rb}$ receptors in the hypothalamic nuclei [12]. Ob$\mathrm{Rb}$ is the long isoform leptin receptor with full intracellular signal transduction capacity, and, similar to other members of the class 1 cytokine receptor family, the predominant signalling mechanism involves a Janus kinase (JAK)/signal transducer and an activator of transcription (STAT) pathway. In response to leptin, $\mathrm{Ob}-\mathrm{Rb}$ undergoes JAK2-mediated phosphorylation, creating docking sites for cytoplasmic STAT3 molecules. Once recruited to the docking sites, STAT3 molecules become phosphorylated, form dimers, and translocate to the nucleus, where they regulate the expression of genes associated with energy expenditure and appetite $[12,13]$. Direct evidence for the role of phosphorylated STAT3 in central energy homeostasis comes from studies involving the targeted deletion of STAT3 in mice. The lack of expression of STAT3 hampers leptin signalling and causes obesity [14].

Nevertheless, most individuals with polygenic obesity present hyperleptinemia and are poorly responsive to the weight lowering and anorexigenic effects of leptin [15]. These are characteristics of leptin resistance in overweight or obese subjects who become resistant to high levels of circulating leptin [16].

The present study hypothesises that the offspring from dams fed a high-fat diet during pregnancy and lactation develop features similar to metabolic syndrome in humans. It is possible that the development of a metabolic syndrome in this model is associated with leptin resistance, which could be reflected by single or combined abnormalities in the expression of proteins involved in leptin signalling in the mediobasal hypothalamus.

\section{Animals and Methods}

\section{Animals}

The experiments were conducted under the guideline of 'Care and Use of Laboratory Animals' published by the US National Institutes of Health. Ethical approval of all the studies was granted by the State University of Rio de Janeiro. Female and male C57BL/6 mice were used from colonies maintained at the Laboratory of Morphometry, Metabolism and Cardiovascular Disease (www.lmmc.uerj.br) located at the State University of Rio de Janeiro. All the animals were housed in temperature and humiditycontrolled cages with a constant light-dark cycle (lights on at 1 a.m., lights off at 1 p.m.). The animals received water 'ad libitum', and diet acceptance and health conditions were evaluated daily. The C57BL/6 mouse has been chosen due to its propensity to develop obesity and dysregulation of glucose metabolism when fed HF [17].

\section{Dam Groups}

Dams were mated with one male per cage overnight, and two groups of dams were used to produce all the offspring. After mating, the female mice were housed individually, and the dietary intervention was started regardless of confirmed pregnancy. Two types of diet were used in this study: (1) standard chow (19\% fat, SC) and (2) HF (49\% fat). The mineral and vitamin contents in the two diets (SC and HF) were identical and in accordance with the American Institute of Nutrition recommendation to support growth during the pregnancy, lactation and post-weaning phases of life (AIN-93G, table 1) [18]. The diets were custom-made by Pragsolucoes Ltda. (www.pragsolucoes.com.br; Jau, Brazil) and were changed daily due to the high content of fat, which predisposes the chow to rot.

The dietary schedules were maintained during gestation and lactation. Later, if pregnancy was not confirmed, the female mice were euthanized. The assessment of maternal body mass was performed weekly during gestation and lactation. The maternal food intake was measured daily during the same period.

The body mass and food intake of the pregnant dams were evaluated during gestation and lactation at weaning, fasting glucose, total cholesterol (TC), triglycerides and leptin levels were measured. 


\section{Offspring Groups}

Immediately after delivery, the gender of the pups was identified by anogenital distance examination, their weights were measured, and the litters were adjusted to 6 animals per mother (to grant adequate and similar nutrition for each pup during nursing). Nursing dams and offspring were kept together in individual cages for 21 days, which corresponds to the lactation period.

At weaning, one male pup per litter was randomly assigned to form the groups of study. Only male pups were utilised in the studies of this paper to exclude complications of sexual dimorphism. The offspring from SC and HF dams were randomly separated into four postnatal groups, according to the combination of diets given to the dams (first acronym) and their respective offspring (second acronym): SC/SC, SC/HF, HF/SC, and HF/HF. The offspring were fed the indicated diet schedule for 105 days, corresponding to the first 3 months of life. A total of 30 animals were included in each group so that several different analyses could be performed. Six animals from each group were subjected to an analysis of metabolic alterations, while the remaining 24 animals were used for analysis of leptin sensitivity. These 24 animals were divided into two groups (vehicle, $\mathrm{n}=12$ or leptin, $\mathrm{n}=12$ ) for the evaluation of the feeding response to leptin $(n=6)$ or STAT3 and pSTAT3 expression $(n=6)$. For clarity, a detailed depiction of the study design is shown in figure 1 .

\section{Body Mass, Food Intake and Feeding Efficiency}

Offspring body mass evolution was measured at birth, at weaning and during the 9 weeks post-weaning, and development curves were plotted using these weights. The measurement of food intake and replenishment of food containers was performed daily at $11 \mathrm{a} . \mathrm{m}$. Energy intake was calculated based on the energetic value of the diets. The feeding efficiency was calculated as grams of body mass gained per kilojoule of food consumed per animal.

\section{Blood Pressure}

Measurements of systolic blood pressure were taken non-invasively in conscious mice at day 105 after birth using tail-cuff plethysmography. The average of three measurements for each animal was used. Two weeks before the experiment, the animals were placed on the plethysmograph to minimise the stress caused by the procedure (Letica LE 5100, Panlab, Barcelona, Spain).

\section{Fasting Glucose and Oral Glucose Tolerance Test}

An oral glucose tolerance test (OGTT) was performed 106 days after birth in all the offspring groups. The mice were fasted for $6 \mathrm{~h}$ before glucose administration. Glucose $(1 \mathrm{~g} / \mathrm{kg})$ was given orally at time 0 ; tail blood was collected at fasting (i.e., baseline) and then 15, 30, 60 and 90 min after glucose loading for plasma glucose determination (Glucometer Accu-Chek Active; Roche Diagnostic, Germany). The area under the curve (AUC; millimolar per minute) was calculated. The values of the glucose concentrations at time 0 were used to determine the fasting glycemia.

\section{Serum Insulin and Leptin}

After diet schedules and 'in vivo' tests, the mice received heparin $(200 \mathrm{mg} / \mathrm{kg}$ ) and deep anesthesia (sodium pentobarbital intraperitoneally, $100 \mathrm{mg} / \mathrm{kg}$ ). The thorax was opened to allow blood sampling from the right atrium. Immediately after the blood draw, plasma was separated from the blood by centrifuga-

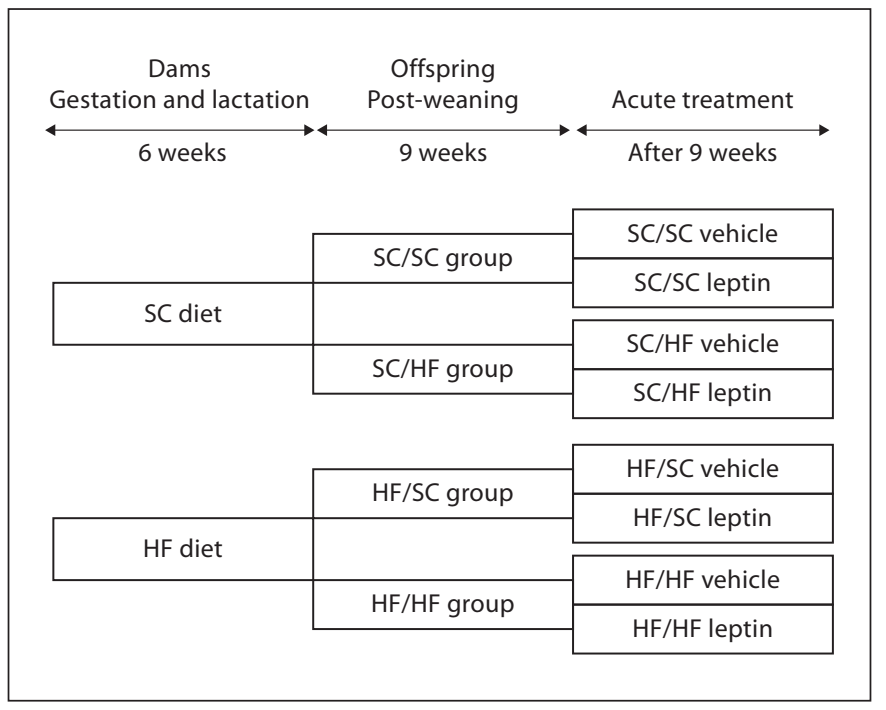

Fig. 1. Experimental design. $\mathrm{SC}=$ Standard chow; $\mathrm{HF}=$ high-fat diet; SC/SC: SC during all stages; SC/HF: SC during gestation and lactation and HF during post-weaning; HF/SC: HF during gestation and lactation and SC during post-weaning; HF/HF: HF during all stages. At the end of the experiment, the four groups were divided to receive ICV vehicle or leptin, resulting in eight groups at the end of the experiment.

tion $(120 \mathrm{~g}$ for $15 \mathrm{~min})$ at room temperature and stored at $-80^{\circ} \mathrm{C}$ until analysis.

The analysis of mouse serum for insulin and leptin was performed using a commercially available enzyme-linked immunosorbent assay (ELISA) kit (human/mouse insulin and leptin ELISA ready-set-go; Bioscience, San Diego, Calif., USA). Insulin resistance was estimated by homeostasis model assessment for insulin resistance INDEX (HOMA-IR) as [(fasting glucose $\times$ fasting insulin)/22.5] [19].

\section{Liver Analysis}

Shortly after euthanasia, the liver was rapidly excised, weighed, and sliced into several fragments for independent quantification of triglyceride levels and morphological signs of steatosis. The triglyceride analysis was performed using a colorimetric enzymatic assay kit (Quibasa Ltda., Belo Horizonte, Brazil) and measured with an automated spectrophotometer (Bioclin System II, Quibasa Ltda., Belo Horizonte, Brazil). For the stereological quantification of steatosis, independent liver pieces were fixed in freshly prepared $4 \%$ buffered formalin ( $\mathrm{pH}$ 7.2). Random fragments were first embedded in Paraplast plus (Sigma-Aldrich Co., St. Louis, Mo., USA), sectioned at $3 \mu \mathrm{m}$, and then stained with HE. Several slices were cut per fragment, and five microscopic fields per animal were analysed at random. A video-microscopic system (Leica DMRBE microscope with planachromatic objectives; Leica, Wetzlar, Germany) and a test system made up of 36 test points $\left(\mathrm{P}_{\mathrm{T}}\right)$ were used for the analysis [20]. The volume density $(\mathrm{Vv})$ was estimated by point counting for hepatocytes and steatosis: $\mathrm{Vv}$ structure $=\mathrm{P}_{\mathrm{P}}$ structure $/ \mathrm{P}_{\mathrm{T}}$, where $\mathrm{P}_{\mathrm{P}}$ is the number of points that hit the structure, and $\mathrm{P}_{\mathrm{T}}$ is the total test points [21]. 
Fat Mass Depots and Adipocyte Morphometry

The fat depots from different anatomical areas were dissected. Inguinal fat, which is located between the lower part of the rib cage and the mid-thigh, was used as representative subcutaneous fat, and retroperitoneal fat was collected from the posterior abdominal wall near the kidneys and the abdominal portion of the ureters. The lower abdominal fat that was connected to the epididymis was used as the source of epididymal fat. The inguinal (subcutaneous), epididymal and retroperitoneal fat pads were carefully dissected and held in a Petri dish containing saline to avoid tissue drying until they could be weighed individually $[17,21]$.

The adipose tissues from the epididymal depots were fixed in freshly prepared $4 \%$ buffered formalin ( $\mathrm{pH} 7.2)$ and embedded in Paraplast plus (Sigma-Aldrich Co.), sectioned (5 $\mu \mathrm{m}$ thick), and stained with HE. Digital images were obtained from the histological sections, and at least 500 adipocytes per group were randomly analysed. The cell diameters were measured by imaging analysis using Image-Pro Plus 7.0 software (Media Cybernetics, Inc., Bethesda, Md., USA).

\section{Acute Feeding Response to Leptin}

Leptin sensitivity and resistance were assessed through the acute feeding response to leptin administered directly into the lateral cerebral ventricle [22]. C57BL/6 mice bearing lateral ventricular cannulae were used to test the acute effects of leptin on the feeding behaviour. For the cannulation of the lateral cerebral ventricle, the mice were anesthetised with ketamine and xylazine and placed on a stereotaxic device (EFF-333, Insight Equipments, Sao Paulo, Brazil). A 30-gauge cannula was placed in the lateral ventricle using the following coordinates: $1.0 \mathrm{~mm}$ lateral, -0.3 $\mathrm{mm}$ posterior, and $-3.0 \mathrm{~mm}$ ventral to the bregma [23]. The proper placement of the cannula in the lateral ventricle was confirmed by inserting methylene blue dye in the first two animals modified and destined for testing. After surgery, the animals were allowed to recover for 1 week before further study.

The offspring were assigned to receive ICV microinjections of either leptin ( $5 \mu \mathrm{g}$ dissolved in $1 \mu \mathrm{l}$ of saline, Sigma-Aldrich Co.) or vehicle ( $1 \mu \mathrm{l}$ of saline). All the animals were fasted for $18 \mathrm{~h}$ before the microinjection administrations because fasting potentiates leptin sensitivity. The chosen dose of leptin is in accordance with previous publications [24]. The feeding response was observed at 4 and $24 \mathrm{~h}$ after the ICV administration of leptin.

\section{Leptin Signalling Expression}

To compare the hypothalamic leptin sensitivity among the eight groups, STAT3 phosphorylation levels were measured on the hypothalamic extracts from starved animals killed $2 \mathrm{~h}$ after a leptin or saline ICV bolus. The mediobasal hypothalamus was carefully dissected, snap frozen in liquid nitrogen and stored at $-80^{\circ} \mathrm{C}$ until the analysis. The expression of intracellular proteins (STAT3, pSTAT3) related to leptin signalling in the mediobasal hypothalamus were measured using Western blot [25]. The total hypothalamic proteins were extracted in homogenising buffer with protease inhibitors. The homogenates were centrifuged for $20 \mathrm{~min}$ at $4^{\circ} \mathrm{C}$, and the supernatants were collected. Equal quantities of total protein were resuspended in sodium dodecylsulfate (SDS)-containing sample buffer, heated for $5 \mathrm{~min}$ at $100^{\circ} \mathrm{C}$, and separated by SDS-polyacrylamide gel electrophoresis. After electrophoresis, the proteins were electroblotted onto a polyvinyldifluoride transfer membrane (Amersham Biosciences, Piscataway, N.J., USA). The efficiency of the transfer was visualised by Ponceau solution staining. The membranes were blocked by incubation with nonfat dry milk (6\% in Tween 20 - Tris-buffered saline), incubated with polyclonal antibody against anti-rabbit tSTAT3 and pJAK2 (97 kDa, SC-483; Santa Cruz Biotechnology, Santa Cruz, Calif., USA) and anti-mouse pSTAT3 and JAK2 (80 kDa, SC-8059; Santa Cruz Biotechnology), washed, and incubated with anti-rabbit and anti-mouse secondary antibodies. The protein levels were detected using an enhanced chemiluminescence detection system (Amersham Biosciences). The signals were visualised by autoradiography and determined by the quantitative analysis of the digital images of gels using ImageJ software, version 1.44 (NIH, imagej.nih.gov/ij, USA). The integral optical density values were measured. STAT3 phosphorylation levels were normalized to total STAT3. A significant elevation of this ratio in leptin-injected animals was taken as an index of the central responsiveness towards leptin [25].

\section{Data Analyses}

The data are expressed as the mean and standard error of mean (SEM). The statistical analysis was performed using the Student $t$ test, a one-way ANOVA with a post hoc Tukey test and with two-way and three-way ANOVA where appropriate (GraphPad Prism 5.03; GraphPad Software, La Jolla, Calif., USA). A p value $<0.05$ was considered statistically significant.

\section{Results}

\section{Maternal Data}

All the HF mothers tolerated the diet and did not have other complications. No significant differences were found in the body mass gain and food intake during the gestation and lactation periods in both SC and HF dams (data not shown). However, the HF dams showed higher levels of TC, fasting glucose and leptin ( $\mathrm{p}<0.05$, $\mathrm{p}<$ 0.001 , and $\mathrm{p}<0.001$, respectively) in comparison with the SC dams. These data are presented in table 2.

\section{Offspring Data}

Body Mass, Feeding Efficiency and Blood Pressure

All the animals subjected to diet interventions tolerated the diet without physical complications. High-fat intervention during pregnancy and lactation did not exert an effect upon offspring body mass at birth or at the end of lactation (21 days of age) (fig. 2). Nevertheless, the offspring showed differences in body mass starting at the 4th week, when the animals from the HF/SC and HF/HF groups were significantly heavier than those of the SC/SC ( $\mathrm{p}<0.001$ in both cases) and SC/HF $(\mathrm{p}<0.001$ in both cases) groups. Between the 5th and the 7th week, offspring from the $\mathrm{SC} / \mathrm{HF}, \mathrm{HF} / \mathrm{SC}$ and $\mathrm{HF} / \mathrm{HF}$ groups were heavier than those of the SC/SC group $(\mathrm{p}<0.001)$. Nota- 
Table 2. Characteristics of dams and male offspring from SC and HF dams

\begin{tabular}{|c|c|c|c|c|}
\hline \multirow[t]{2}{*}{ Data } & \multicolumn{4}{|l|}{ Dams } \\
\hline & \multicolumn{2}{|l|}{ SC } & \multicolumn{2}{|l|}{$\mathrm{HF}$} \\
\hline Glucose, mmol/l & \multicolumn{2}{|l|}{$6.45 \pm 0.11$} & \multicolumn{2}{|l|}{$8.29 \pm 0.21^{*}$} \\
\hline $\mathrm{TC}, \mathrm{mg} / \mathrm{dl}$ & \multicolumn{2}{|l|}{$80.80 \pm 3.31$} & \multicolumn{2}{|l|}{$122.20 \pm 6.28^{*}$} \\
\hline $\mathrm{TG}, \mathrm{mg} / \mathrm{dl}$ & \multicolumn{2}{|l|}{$54.80 \pm 5.38$} & \multicolumn{2}{|l|}{$56.80 \pm 1.39$} \\
\hline Leptin, ng/ml & \multicolumn{2}{|l|}{$1.65 \pm 0.42$} & \multicolumn{2}{|l|}{$3.71 \pm 0.08^{*}$} \\
\hline \multirow[t]{2}{*}{ Data } & \multicolumn{4}{|l|}{ Offspring } \\
\hline & SC/SC & $\mathrm{SC} / \mathrm{HF}$ & $\mathrm{HF} / \mathrm{SC}$ & $\mathrm{HF} / \mathrm{HF}$ \\
\hline $\mathrm{FE}, \mathrm{g} / \mathrm{KJ}\left(\times 10^{-2}\right)$ & $3.67 \pm 0.09$ & $4.89 \pm 0.13^{\mathrm{a}}$ & $3.35 \pm 0.23$ & $3.35 \pm 0.15$ \\
\hline $\mathrm{TC}, \mathrm{mg} / \mathrm{dl}$ & $88.8 \pm 3.0$ & $120 \pm 8.2^{\mathrm{a}}$ & $110 \pm 1.94^{\mathrm{a}}$ & $133 \pm 3.20^{\mathrm{a}, \mathrm{c}}$ \\
\hline $\mathrm{BP}, \mathrm{mm} \mathrm{Hg}$ & $147 \pm 5.3$ & $152 \pm 2.9$ & $157 \pm 1.3$ & $178 \pm 1.3^{\mathrm{a}-\mathrm{c}}$ \\
\hline $\mathrm{LM}, \mathrm{g} / \mathrm{cm}$ & $1.88 \pm 0.07$ & $2.29 \pm 0.12^{\mathrm{a}}$ & $2.31 \pm 0.09^{\mathrm{a}}$ & $2.29 \pm 0.06^{\mathrm{a}}$ \\
\hline Hepatic TG, mg/dl & $112 \pm 6.87$ & $215 \pm 21.8^{\mathrm{a}}$ & $166 \pm 6.7^{\mathrm{a}, \mathrm{b}}$ & $265 \pm 3.7^{a-c}$ \\
\hline OGTT, AUC & $1,111 \pm 39.2$ & $1,278 \pm 111.7$ & $1,017 \pm 40.3$ & $1,521 \pm 149.9^{a, c}$ \\
\hline Insulin, ng/dl & $0.54 \pm 0.01$ & $1.73 \pm 0.26^{\mathrm{a}}$ & $1.71 \pm 0.36^{\mathrm{a}}$ & $1.79 \pm 0.31^{\mathrm{a}}$ \\
\hline HOMA IR, $\mu \mathrm{U} / 1$ & $4.07 \pm 0.14$ & $16.0 \pm 2.46^{\mathrm{a}}$ & $13.7 \pm 2.58^{\mathrm{a}}$ & $15.8 \pm 3.19^{a}$ \\
\hline
\end{tabular}

Values are shown as means \pm SEM. Superscripts represent a significant difference $(\mathrm{p}<0.05)$ : in dams compared with the SC dams $\left(^{*}\right)$; in offspring compared with the SC/SC group (a), the SC/HF group (b), the HF/SC group (c), and the HF/HF group (d). FE = feed efficiency; TC = total cholesterol; $\mathrm{BP}=$ blood pressure; $\mathrm{LM}=$ liver mass; TG = triglycerides; OGTT = oral glucose tolerance test; HOMA IR = homeostasis model assessment for insulin resistance index.

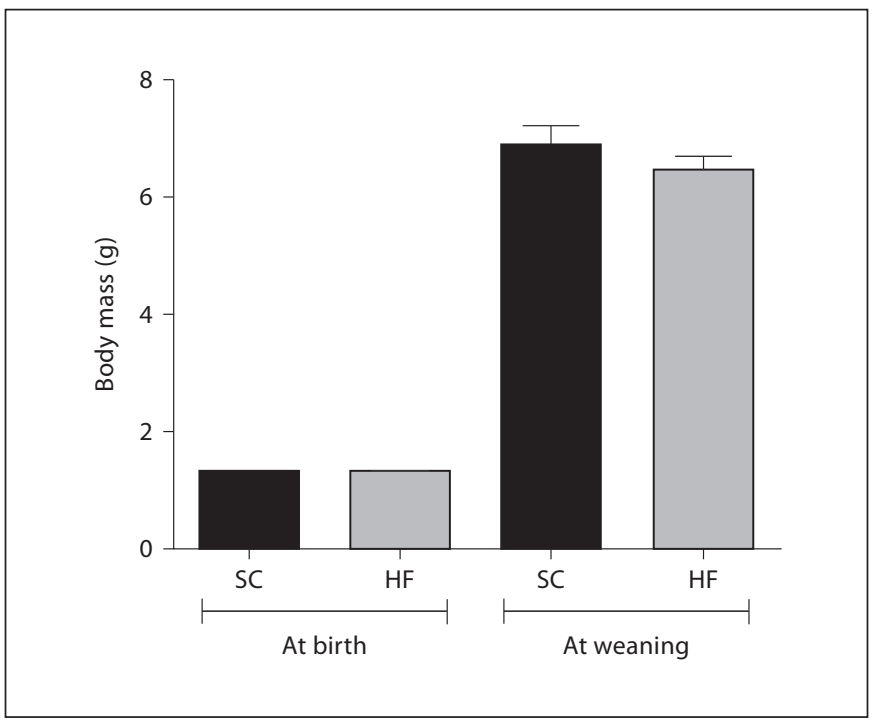

Fig. 2. Offspring body mass at birth and at weaning. SC: offspring from SC dams; HF: offspring from HF dams. Values are shown as means \pm SEM, t test. bly, at the 5th week, the HF/HF mice showed even more pronounced differences compared to the SC/HF ( $\mathrm{p}<$ $0.001)$ and HF/SC $(\mathrm{p}<0.001)$ mice. Significant differences were evident at the 7 th week between the HF/HF and $\mathrm{HF} / \mathrm{SC}$ groups $(\mathrm{p}<0.01)$. At the 8 th week, the $\mathrm{HF} / \mathrm{HF}$ and $\mathrm{SC} / \mathrm{HF}$ offspring had the greatest body masses and were significantly different from the SC/SC group $(p<0.001)$. These differences were maintained until the 12th week, when they became even more apparent. Importantly, the $\mathrm{HF} / \mathrm{SC}$ offspring showed an increase in body mass when compared with the SC/SC group at the 11th and 12th week of age ( $p<0.001$ and $p<0.001$, respectively). At the end of the experiment, compared to the SC/SC offspring, the body mass was $22 \%$ greater in the SC/HF offspring, $10 \%$ greater in the HF/SC offspring, and $16 \%$ greater in the HF/HF offspring (fig. 3). Of note, there was an interaction between maternal HF and post-weaning HF, with major influence of post-weaning diet on body mass values ( $p<0.0001$, two-way ANOVA). The SC/HF offspring presented higher feeding efficiency values than the SC/ SC offspring ( $\mathrm{p}<0.01)$ (table 2$)$, suggesting a mechanism to explain the increase in body mass. 
At 3 months of age, perinatal and post-weaning HF played a role in triggering hypertension in the mice. The $\mathrm{HF} / \mathrm{HF}$ offspring had higher BP levels by 3 months than the SC/SC $(+21 \%$; $<<0.001), S C / H F(+17 \%$; $p<0.001)$ and $\mathrm{HF} / \mathrm{SC}$ offspring (+13\%; $\mathrm{p}<0.01$; table 2$)$. Moreover, there was interaction between the HF schedules, and the greatest influence of maternal diet was found for this feature $(\mathrm{p}<0.05$, two-way ANOVA).

Total Cholesterol, Glucose, OGTT, Insulin and HOMA-IR

The values of TC were similar among and higher in the SC/HF (+36\%; p < 0.01), HF/SC $(25 \%$; p < 0.05) and HF/ HF offspring (51\%; $p<0.001)$, when compared with the $\mathrm{SC} / \mathrm{SC}$ offspring. Fasting glucose concentrations were not affected by the different diet schedules. However, the table shows greater OGTT values in the HF/HF offspring than in the SC/SC $(+36 \%$; p < 0.05) and HF/SC $(49 \%$; p < $0.01)$ offspring groups. Additionally, the SC/HF $(+220 \%$; $\mathrm{p}<0.05), \mathrm{HF} / \mathrm{SC}(+216 \% ; \mathrm{p}<0.05)$, and HF/HF $(+231 \%$; $\mathrm{p}<0.05)$ offspring exhibited higher insulin concentrations when compared with the SC/SC control group. Consequently, the same groups had higher HOMA-IR values than the SC/SC offspring (table 2).

\section{Liver Mass, Hepatic Triglycerides and Stereological}

Quantification

The increased liver mass in animals subjected to perinatal HF, post-weaning HF or both interventions suggested that liver steatosis could be present (table 2). Greater liver masses were observed in the SC/HF $(+21 \%$; $\mathrm{p}<$ $0.05), \mathrm{HF} / \mathrm{SC}(+22 \%$; $\mathrm{p}<0.01)$ and $\mathrm{HF} / \mathrm{HF}$ offspring $(+21 \%$; $p<0.01)$ when compared with the SC/SC offspring. Even though the liver mass values were close, the effects of HF during development were different considering the amount of hepatic triglycerides (table 2). The SC/HF (+91\%; p < 0.001), HF/SC $(48 \%$; $<<0.05)$ and HF/ HF groups $(136 \%$; $\mathrm{p}<0.001)$, which were all exposed to a HF diet, presented higher values compared to the SC/SC animals. Notably, values from the HF/HF group were even more pronounced, displaying a significant difference when compared with the SC/HF $(+23 \%$; $\mathrm{p}<0.05)$ and $\mathrm{HF} / \mathrm{SC}$ groups $(+59 \%$; $\mathrm{p}<0.001)$. The presence of liver steatosis was confirmed in the SC/HF, HF/SC and $\mathrm{HF} / \mathrm{HF}$ groups using stereological quantification (fig. 4). The SC/SC group had few indications of liver steatosis $(12.4 \pm 0.98 \%)$, an amount that could be considered normal. Steatosis was substantial in the SC/HF, HF/SC and $\mathrm{HF} / \mathrm{HF}$ groups $(\sim 34, \sim 25$, and $\sim 40 \%$, respectively) and can be directly observed in the photomicrographs (fig. 5).

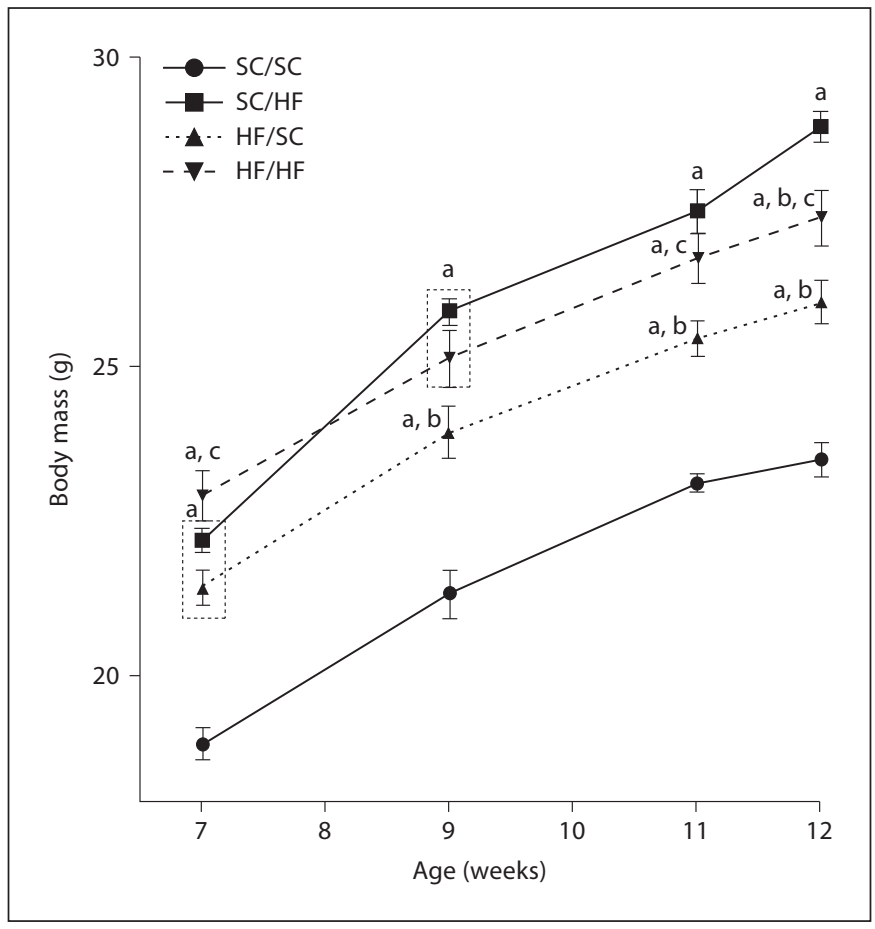

Fig. 3. Body mass evolution in offspring groups, analyzed by oneway ANOVA and Tukey's post hoc test. Values are shown as means \pm SEM. Symbols represent a significant difference $(\mathrm{p}<$ $0.05)$ compared with the SC/SC group (a), the SC/HF group (b), the HF/SC group (c), and the HF/HF group (d).

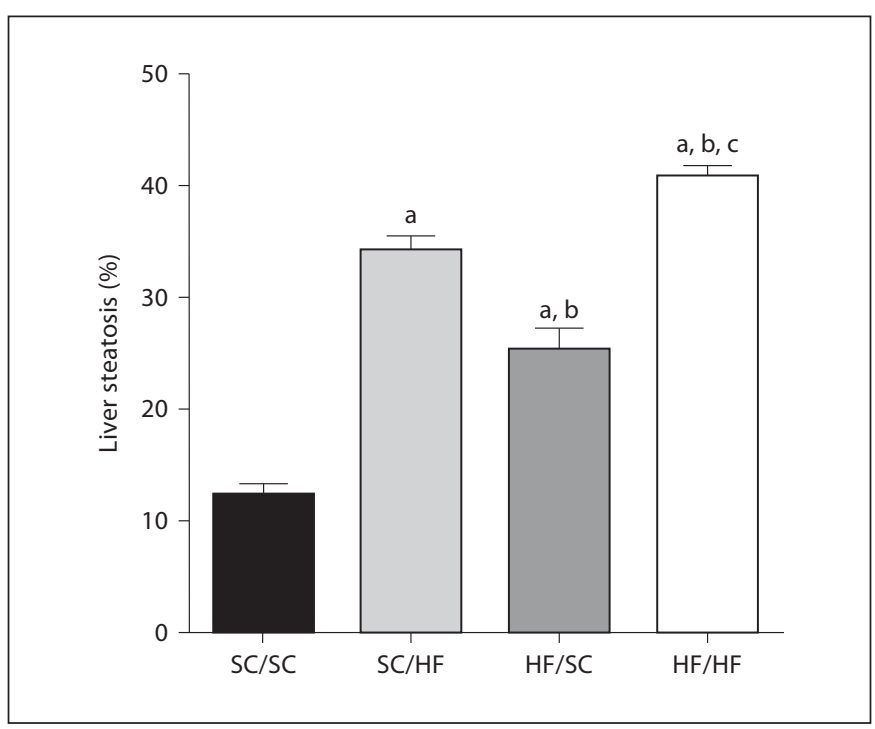

Fig. 4. Liver steatosis. Stereological quantification analyzed by one-way ANOVA and Tukey's post hoc test. Values are shown as means \pm SEM. Symbols represent a significant difference $(\mathrm{p}<$ $0.05)$ compared with the SC/SC group (a), the SC/HF group (b), the HF/SC group (c), and the HF/HF group (d). 
Fig. 5. Photomicrographs of the 3-monthold male liver tissue (HE stain) with different patterns of liver steatosis: SC/SC group (a), SC/HF group (b), HF/SC group (c), $\mathrm{HF} / \mathrm{HF}$ group (d).
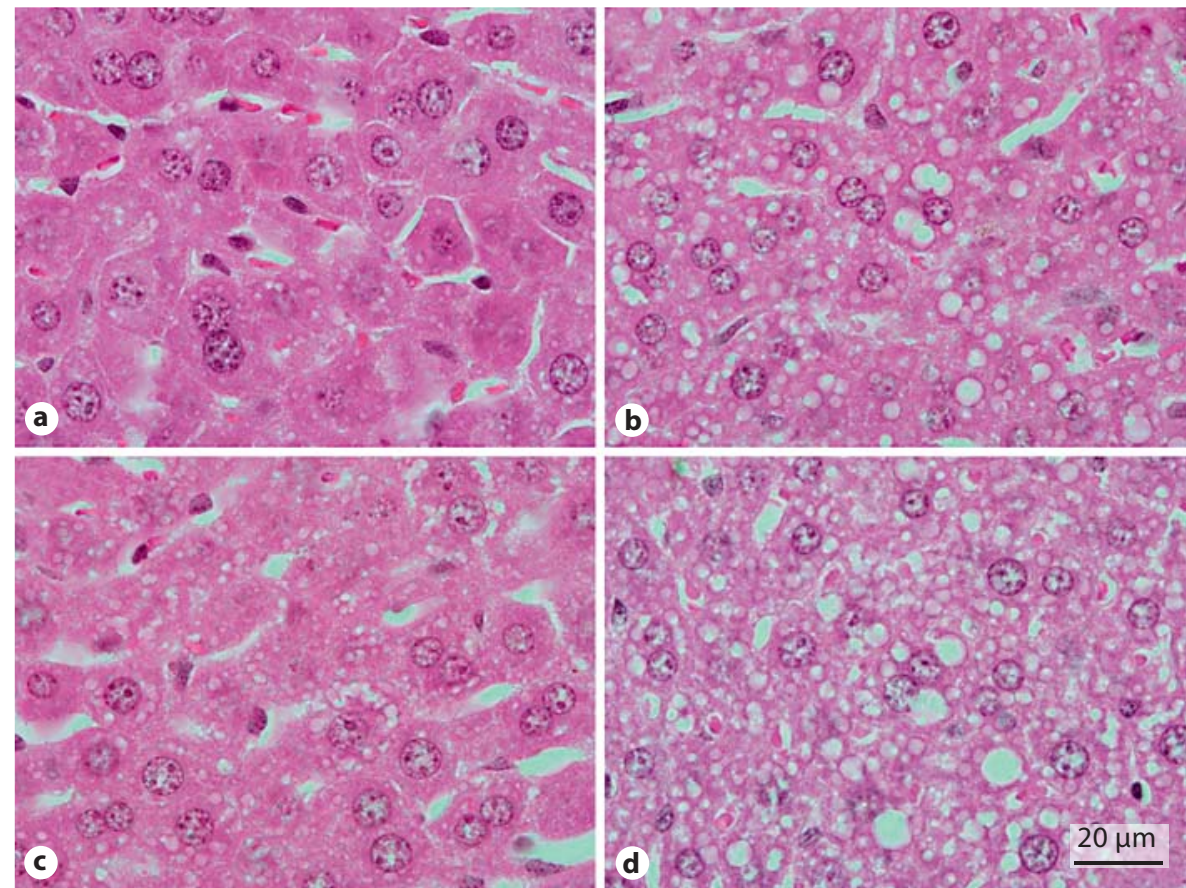

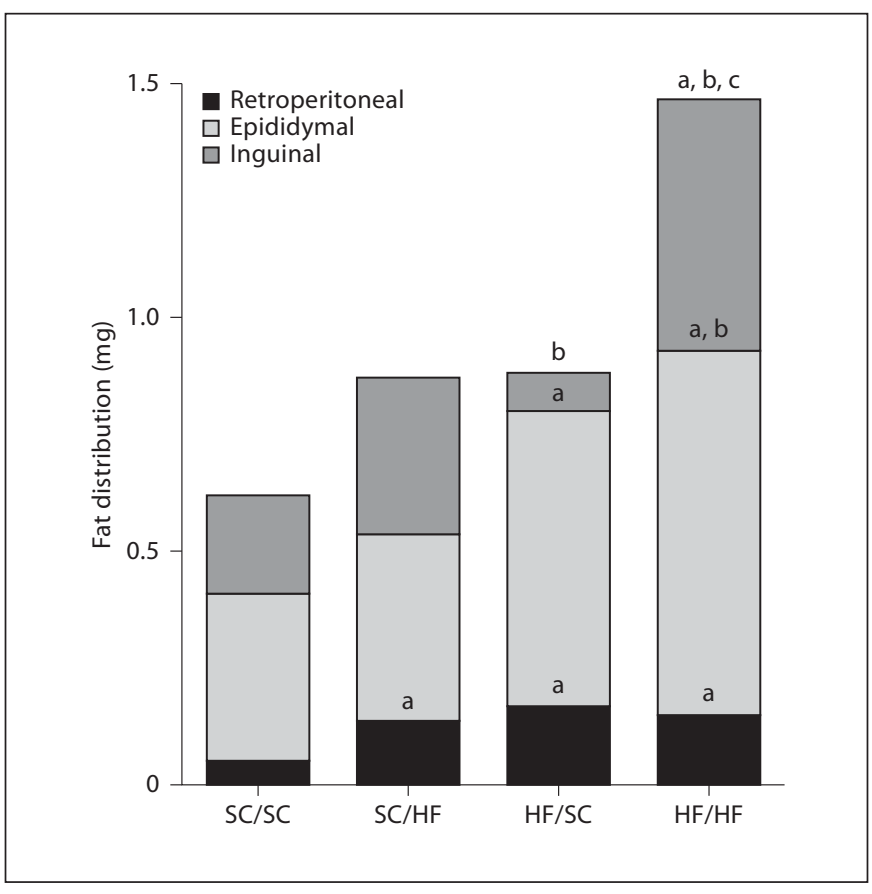

Fig. 6. Fat distribution analyzed by one-way ANOVA and Tukey's post hoc test. Values are shown as means. Symbols represent a significant difference $(\mathrm{p}<0.05)$ compared with the SC/SC group (a), the SC/HF group (b), the HF/SC group (c), and the HF/HF group (d).
We observed statistically significant interactions among the feeding routines, with the post-weaning diet exerting a major influence on liver steatosis $(p<0.005$, two-way ANOVA).

Fat Depots, Visceral/Subcutaneous Ratio, Adipocyte Morphometry and Plasma Leptin Levels

Our results demonstrate that high-fat programming influences adipose tissue architecture and distribution (fig. 6). The amount of retroperitoneal fat was increased in the SC/HF $(+225 \%$; $\mathrm{p}<0.05), \mathrm{HF} / \mathrm{SC}(+300 \%$; $\mathrm{p}<0.01)$ and $\mathrm{HF} / \mathrm{HF}(+250 \%$; $\mathrm{p}<0.01)$ groups when compared with the SC/SC control group. We observed evidence for an interaction between the maternal and post-weaning diets, indicating the key role of HF diet during early life on the amount of retroperitoneal fat $(\mathrm{p}<0.003$, two-way ANOVA). HF programming in the HF/SC (+80\%; p < $0.05)$ and $\mathrm{HF} / \mathrm{HF}$ groups $(120 \%$; $\mathrm{p}<0.01)$ led to a larger epididymal fat pad than in the SC/SC animals. The HF/ HF group also had larger epididymal fat pads than the SC/HF group (+61\%; $\mathrm{p}<0.01)$. Meanwhile, the HF/SC group had a decrease $(-76 \%$; $<<0.01)$ in inguinal fat depots, as compared with the SC/HF group. The HF/HF group had the highest inguinal fat pad mass, compared with the SC/SC (+151\%; p < 0.001), SC/HF (35\%; p < $0.05)$ and HF/SC groups (562\%; p < 0.001). The postweaning HF diet had a major influence on the inguinal 
fat depot mass ( $p<0.001$, two-way ANOVA). We combined the fat deposit data into a metric known as the visceral/subcutenous ratio (detailed in figure 7), which indicates the pattern of fat distribution in each group. Using this metric, the HF/SC offspring showed the greatest values when compared with the SC/SC $(+467 \%$; p < $0.001), \mathrm{SC} / \mathrm{HF}(+605 \%$; $\mathrm{p}<0.001)$ and $\mathrm{HF} / \mathrm{HF}$ groups $(+521 \%$; $<<0.001)$.

A microscopic analysis of adipose tissue showed adipocyte hypertrophy in both the HF/SC and $\mathrm{HF} / \mathrm{HF}$ offspring when compared to the SC/SC $(+29 \%, \mathrm{p}<0.001$; $+24 \%, \mathrm{p}<0.001$, respectively) and $\mathrm{SC} / \mathrm{HF}$ offspring $(+20 \%, \mathrm{p}<0.001 ;+15 \%, \mathrm{p}<0.001$, respectively) (fig. 8). In contrast, hypertrophy was less prominent in the SC/HF offspring, with an increase of $7 \%$ compared to the SC/SC offspring $(\mathrm{p}<0.01)$. There was a statistically significant interaction between feeding schedules, with a substantial influence of the maternal diet ( $\mathrm{p}<0.0001$, two-way ANOVA). The morphological differences in the adipocytes are depicted in the micrographs in figure 9.

Plasma leptin concentrations were elevated in the SC/ HF (+131\%; p < 0.001), HF/SC $(+82 \%$; $<<0.001)$ and HF/ HF offspring $(+156 \%$; $p<0.001)$ when compared with the SC/SC offspring. The leptin concentrations in groups that received the post-weaning HF diet were more accentuated, with an increase of $26 \%$ in the SC/HF $(\mathrm{p}<0.05)$ and $40 \%$ in $\mathrm{HF} / \mathrm{HF}(\mathrm{p}<0.001)$ offspring relative to the $\mathrm{HF} / \mathrm{SC}$ offspring (fig. 10). Also, the major influence of the post-weaning $\mathrm{HF}$ on the leptin concentrations was demonstrated by running two-way ANOVA $(\mathrm{p}<0.01)$.

Food Intake after ICV Treatment with Leptin

The animals from the SC/SClep and HF/SClep offspring ate less $(-57 \%, \mathrm{p}<0.05 ;-71 \%, \mathrm{p}<0.001$, respectively) $4 \mathrm{~h}$ following the microinjection of leptin compared to their respective control groups (SC/SCveh and $\mathrm{HF} / \mathrm{SCveh}$ ). Likewise, after $24 \mathrm{~h}$, food intake was reduced approximately 55\% in the SC/SClep $(p<0.001)$ and 52\% in the HF/SClep $(\mathrm{p}<0.001)$ offspring. Interestingly, despite the HF routine applied throughout life, the HF/HFlep group was responsive to the anorectic effects of leptin, which reduced food intake by $44 \%$ in comparison with the HF/HFveh group $(\mathrm{p}<0.01) 24 \mathrm{~h}$ after ICV treatment. Additionally, the consumption of HF during post-weaning prevented the anorectic effects of leptin in the SC/ HFlep group (fig. 11). The results from a three-way ANOVA indicate that ICV treatment alone $(\mathrm{p}<0.001)$ or with a post-weaning $(\mathrm{p}<0.01)$ diet were the determinants for the responses.

Maternal High-Fat Diet in Mice

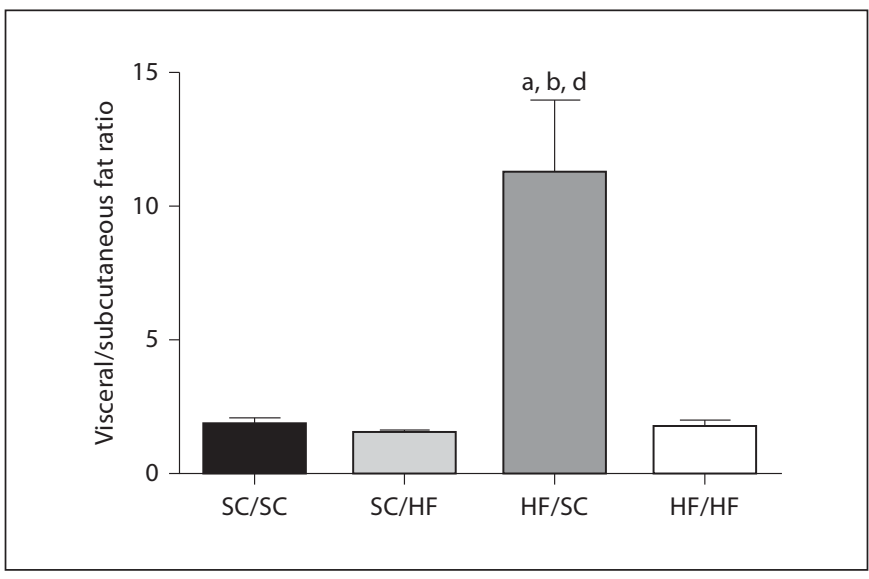

Fig. 7. Visceral/subcutaneous fat ratio analyzed by one-way ANOVA and Tukey's post hoc test. Values are shown as means. Symbols represent a significant difference $(\mathrm{p}<0.05)$ compared with the SC/SC group (a), the SC/HF group (b), the HF/SC group (c), and the HF/HF group (d).

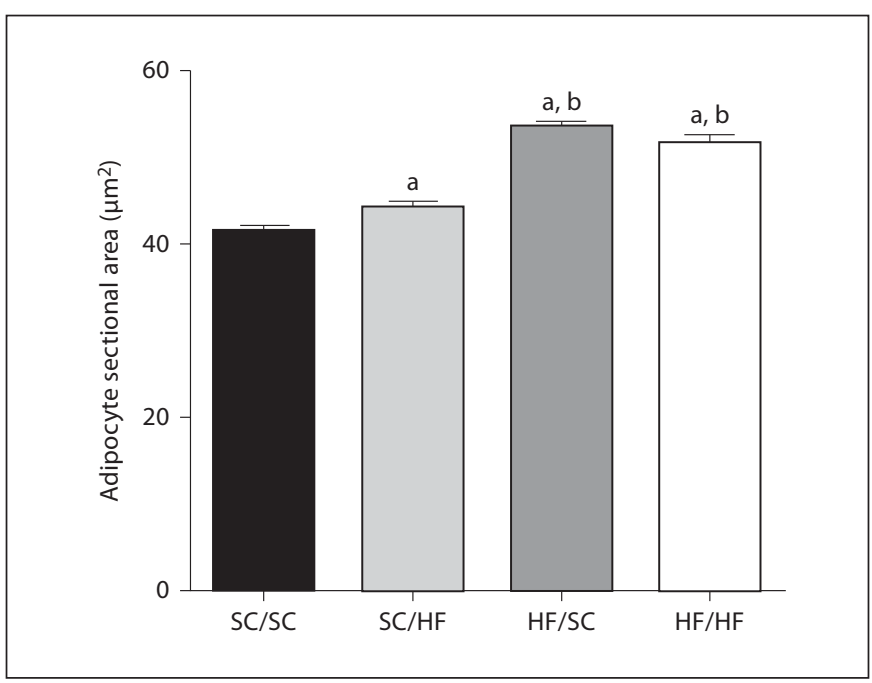

Fig. 8. Adipocyte morphometry. Adipocyte areas were analyzed by one-way ANOVA and Tukey's post hoc test. Values are shown as means \pm SEM. Symbols represent a significant difference $(\mathrm{p}<$ $0.05)$ compared with the SC/SC group (a), the SC/HF group (b), the HF/SC group (c), and the HF/HF group (d).

Leptin-Dependent STAT3 Phosphorylation in the Hypothalamus

We found that leptin administration can upregulate the expression of pSTAT3, but it does not influence levels of total STAT3. The acute ICV treatment with leptin caused a robust increase in the pSTAT3/total STAT3 ratio 
Fig. 9. Photomicrographs of the 3-monthold male adipose tissue (HE stain) with adipocyte size differences: SC/SC group (a), SC/HF group (b), HF/SC group (c), $\mathrm{HF} / \mathrm{HF}$ group (d).

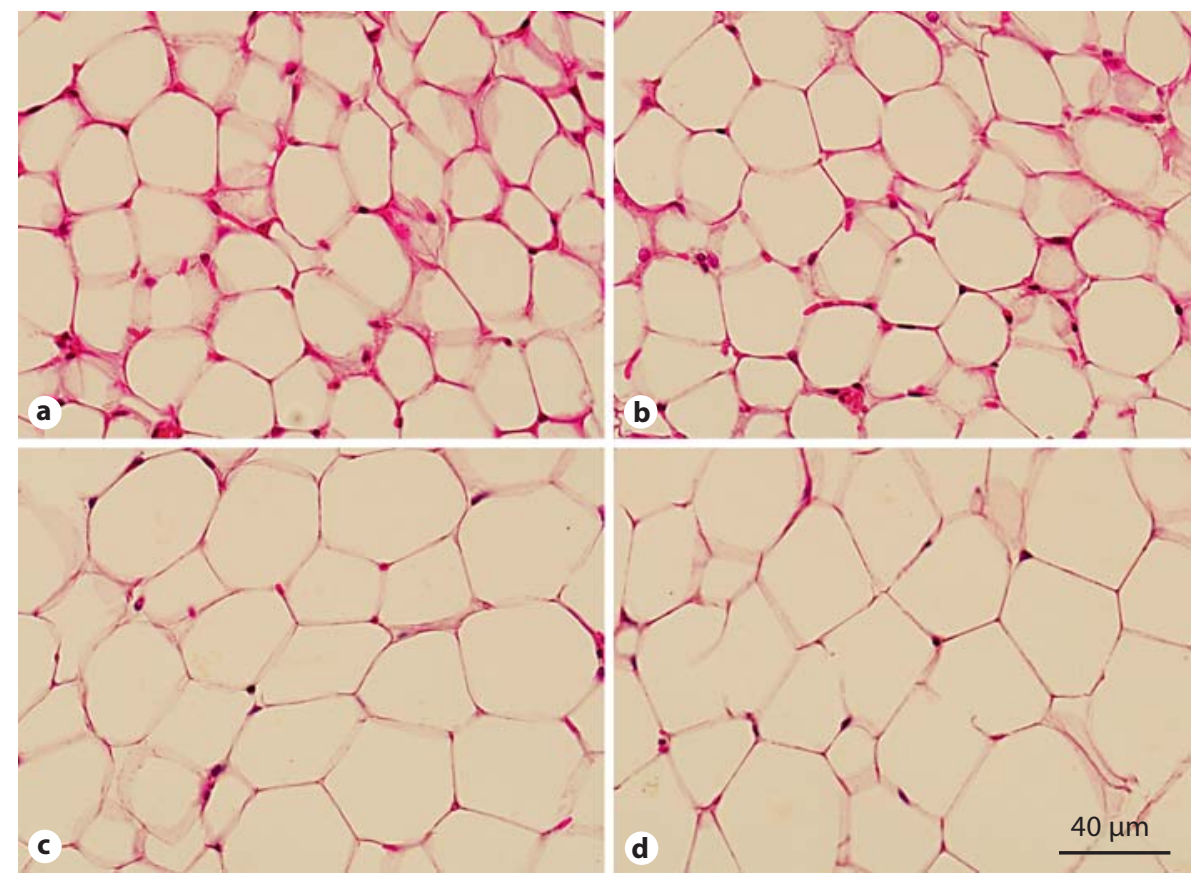

in the mediobasal hypothalamus of the SC/SClep (2.26 \pm 0.33 vs. $0.62 \pm 0.07$ in SC/SCveh, $\mathrm{p}<0.001)$, HF/SClep $(2.53 \pm 0.09$ vs. $0.66 \pm 0.30$ in HF/SCveh, $\mathrm{p}<0.001)$ and $\mathrm{HF} /$ HFlep groups $(2.32 \pm 0.19$ vs. $0.72 \pm 0.07 \mathrm{in} \mathrm{HF/}$ HFveh, $\mathrm{p}<0.001$ ) (fig. 12). All three factors (maternal diet, post-weaning diet or ICV treatment) alone or combined influenced the pSTAT3/STAT3 ratio $(\mathrm{p}<0.01$, three-way ANOVA).

\section{Discussion}

The consumption of HF (mostly saturated fatty acid) content during gestation and lactation promotes the development of obesity and metabolic abnormalities in adult offspring $[5,6]$. In the present study, we hypothesised that the maternal HF schedule determines similar features of metabolic syndrome in humans and leptin resistance in adult male C57BL/6 mice. Although our study did not show an elevation in the maternal body mass or their food intake, the effects of maternal HF in the offspring may be due to an altered intrauterine environment. HF dams had higher cholesterol, glucose and leptin levels, favouring neonatal hyperinsulinism, which is an important teratogenic risk factor [26].

The maternal HF diet had a clear programming effect in the offspring. A HF diet was administered during two

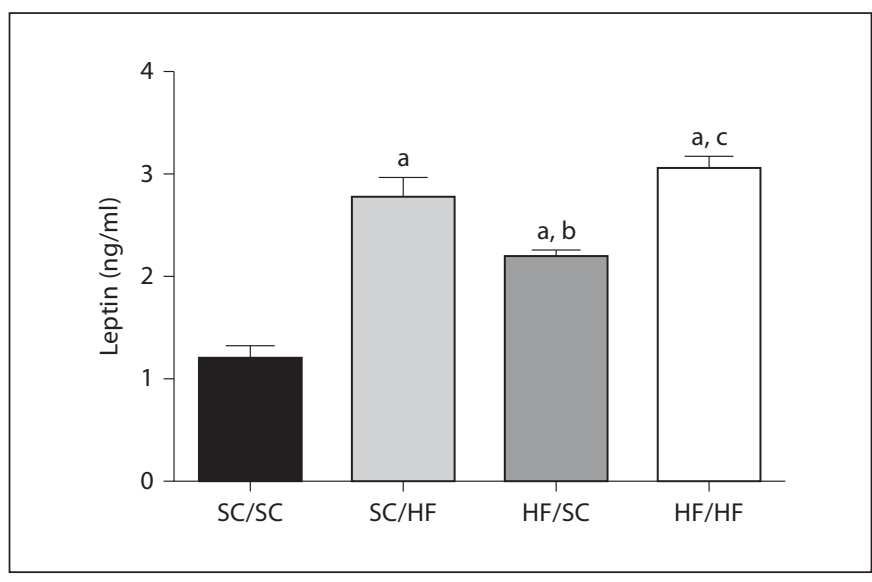

Fig. 10. Leptin concentration in plasma of offspring analyzed by one-way ANOVA and Tukey's post hoc test. Values are shown as means \pm SEM. Symbols represent a significant difference $(\mathrm{p}<$ $0.05)$ compared with the SC/SC group (a), the SC/HF group (b), and the HF/SC group (c).

different periods of rat development: in pregnant and lactating dams and in offspring from post-weaning up to 3 months of age. We tested whether each single period or the combination of a HF diet in the dams and offspring results in deleterious effects to the health of adult offspring. 


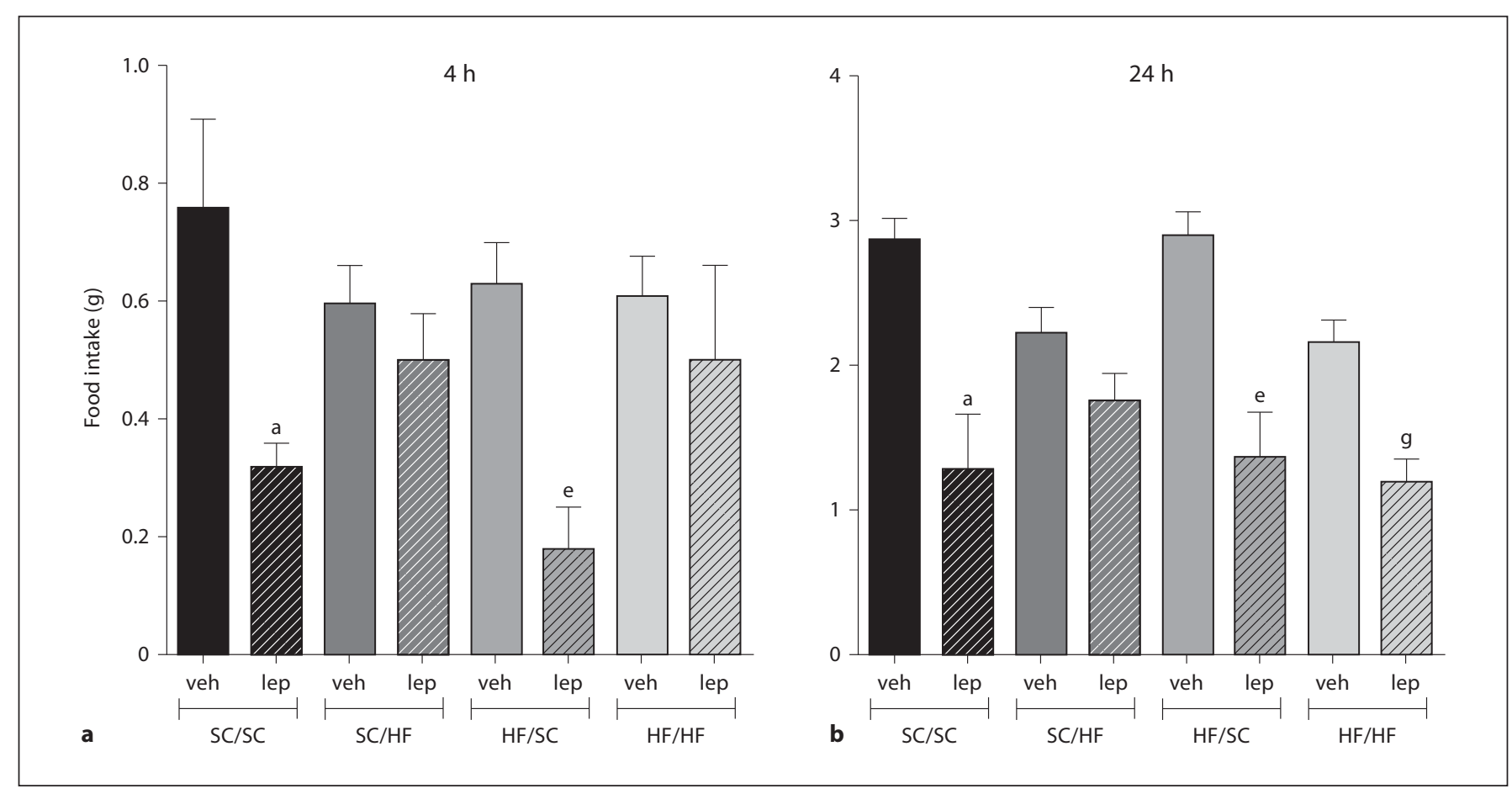

Fig. 11. a Food intake $4 \mathrm{~h}$ after ICV leptin $(5 \mu \mathrm{g})$. b Food intake $24 \mathrm{~h}$ after ICV leptin $(5 \mu \mathrm{g})$. Values are shown as means \pm SEM, t test. Symbols represent a significant difference $(\mathrm{p}<0.05)$ compared with the SC/SCveh $(a)$, the HF/SCveh (e), and the HF/HFveh (g).

Our results indicate that a maternal HF diet does not affect body mass at birth or at weaning (fig. 2). A range of animal experiments in which programming has been induced in offspring by prenatal nutritional or endocrine manipulation has also demonstrated that the effects can be produced in the absence of a change in birth weight $[27,28]$. In the weeks after weaning, the values of offspring body mass diverged. Specifically, at the end of the experiment, a HF diet post-weaning resulted in a higher body mass, followed by HF/HF and HF/SC diets. Higher body mass with the SC/HF diet is certainly in part a consequence of decreased energy expenditure, as indicated by increased feed efficiency (table 2) [29].

Our findings show that carbohydrate metabolism was impaired by a HF diet during pregnancy and lactation or was a result of increased fat intake post-weaning. Specifically, HF/SC animals presented with hyperinsulinemia, which is a prediabetic state. In this situation, $\beta$-cells increase insulin secretion as a compensatory response to insulin resistance [30]. Our data confirm previous demonstrations that critical events during sensitive periods of development may 'program' the longterm or lifetime structure or function of the organism
[31]. Recently, Cerf et al. [32] showed that neonates exposed to a HF diet for the entire duration of pregnancy were hyperglycemic, with reduced $\beta$-cell volume and number. During post-weaning, the SC/HF animals presented higher levels of insulin, indicating that they were not able to normalise their glucose concentrations, which is the second stage in the development of diabetes [30]. Dietary fat affects insulin resistance and $\beta$-cell function in both obesity and type 2 diabetes. Free fatty acids have generally been proposed to regulate pancreatic insulin release by intracellular mechanisms effects on $\beta$-cells, amplifying glucose-stimulated insulin secretion in experimental animal islets [33]. Indeed, in our study, the animals that received a HF diet in both periods (HF/HF) were more affected. These animals presented features similar to the SC/HF animals and had a higher AUC in OGTT, which indicates glucose intolerance. In the majority of the prediabetic population, insulin resistance precedes the development of glucose intolerance [33].

Additionally, insulin resistance is a strong driver of fat accumulation in the liver [34]. Our experimental groups presented relative enlargement of their liver (table 2), re- 


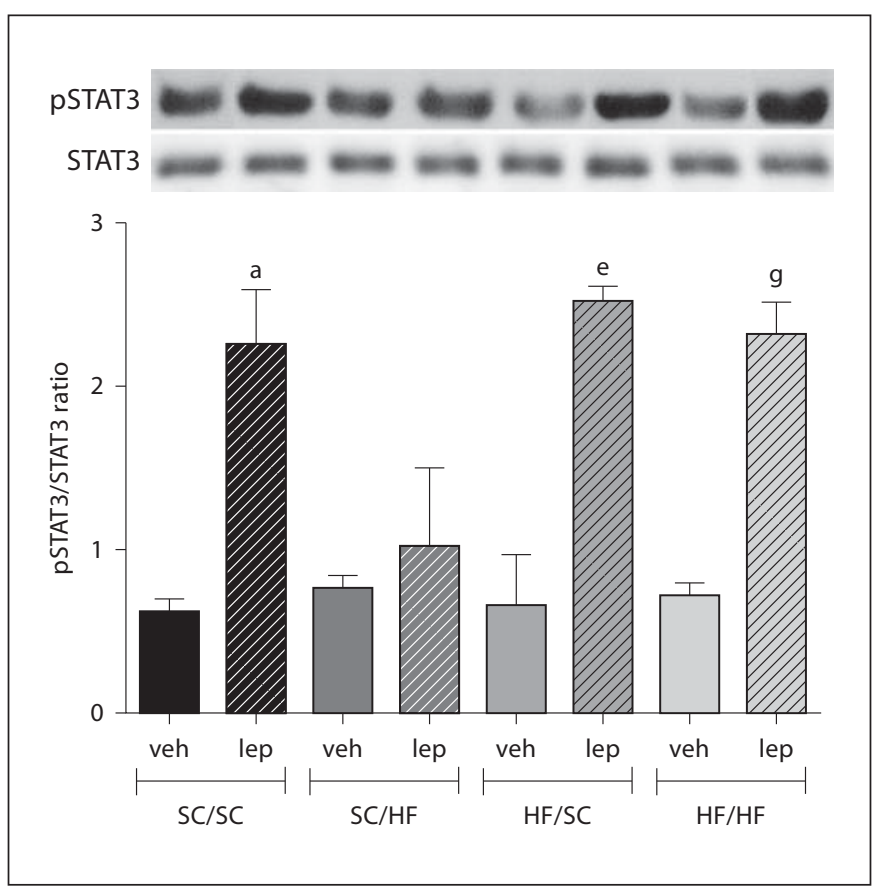

Fig. 12. Leptin activation of STAT3 in the mediobasal hypothalamus after intracerebroventricular administration of leptin $(5 \mu \mathrm{g})$. Data are shown the means \pm SEM. $t$ test. Symbols represent a significant difference $(\mathrm{p}<0.05)$ compared with the SC/SCveh (a), HF/SCveh (e), HF/HFveh (g).

flecting an early sign of the adverse effects of diets rich in saturated fatty acids [35]. Recent studies indicate that increased levels of triglyceride in the liver (steatosis) have also been observed in the adult offspring of dams fed a HF diet, which is in agreement with our findings [36]. Liver steatosis was estimated through stereology and levels of hepatic triglycerides. Perinatal HF animals had substantial liver steatosis (25\%), whereas post-weaning HF animals showed $34 \%$. The HF/HF offspring were the most affected, with approximately $40 \%$ of liver tissue having evidence of steatosis (fig. 4, 5). These findings were confirmed by triglyceride measurements (table 2), which displayed similar differences. Insulin resistance contributes to a hepatic input of fatty acids (either uptake or lipogenesis) that exceeds its own output (degradation or export), favouring the occurrence of fatty liver or hepatic steatosis $[37,38]$. Moreover, some animals, including nonhuman primates and murine models, have been used to correlate the intrauterine environment and development of NAFLD $[39,40]$. The upregulation of specific placental nutrient transporter isoforms was identified as the driving factor [41].
The consumption of a HF diet during gestation and lactation, post-weaning or during both periods promoted an increased amount of retroperitoneal fat. However, a different pattern of distribution was observed in epididymal fat. The HF/SC and HF/HF offspring presented the greatest accumulation and hypertrophy in this compartment. Moreover, inguinal fat (subcutaneous fat) was reduced in the HF/SC group when compared with the $\mathrm{SC} / \mathrm{HF}$ and $\mathrm{HF} / \mathrm{HF}$ groups, whereas the $\mathrm{HF} / \mathrm{HF}$ group had the highest amount of inguinal fat, contributing to the greatest total fat mass in this group (fig. 6). Overall, our results demonstrate that a HF diet during early life (pregnancy and lactation) can amplify the ability to store visceral fat (fig. 7), which is in agreement with previous publications $[42,43]$. In addition, the literature indicates that hyperleptinemia can be associated with total body fat [44] and, specifically, with higher subcutaneous fat [43]. Considering the leptin levels and fat distribution in our study, we can affirm that postnatal nutrition determines the amount of subcutaneous fat and, consequently, the future leptin production in the offspring (fig. 6, $10)$.

Hyperleptinemia is considered a surrogate for central leptin resistance. Recent studies have shown increased levels of leptin in HF-programmed offspring, with changes in leptin signalling in the hypothalamus $[9,45]$. In this view, hypothalamic STAT3 plays a crucial role in the regulation of POMC and AgRP gene expression by leptin [46]. Based on these findings, we could expect attenuated responses to ICV leptin injection in the SC/HF, HF/SC and $\mathrm{HF} / \mathrm{HF}$ groups. However, the only group affected in this feature was the SC/HF group. Surprisingly, the HF/ $\mathrm{SC}$ and $\mathrm{HF} / \mathrm{HF}$ offspring reduced their food intake and had a higher pSTAT3/STAT3 ratio (fig. 11, 12). The differences among the present results and previous studies from other groups are probably due to differences in animal lineage and age and the amount of lipids and the energetic density of the HF diet. Moreover, the sensitivity to leptin in the HF/HF group could also be attributed to a predictive adaptive response. According to this concept, when the postnatal diet is similar to the dam's diet, some of the programming effects can be avoided [27]. It is possible that other neural mechanisms, such as central insulin action, are involved in the development of obesity in our groups [47].

In summary, HF consumption, independent of the period, affects the health of adult offspring. Specifically, this study strongly indicates that the amount of visceral fat, liver steatosis and insulin resistance can be programmed in mice by maternal HF consumption and that 
this condition can be further worsened by post-weaning HF. These alterations were not associated with central leptin resistance due to a different pattern of fat distribution in the HF/SC offspring or as a result of adaptive change in the HF/HF offspring. Our data suggest that post-weaning HF is a determinant for leptin resistance development. Therefore, further investigations are needed to determine the mechanisms underlying HF programming, which may contribute to future prevention and treatment strategies.

\section{Acknowledgements}

The authors thank Thatiany Marinho and Aline Penna for technical support. This research was partially supported by grants E-26/110.265/2010 and 480280/2008-8 from the State Foundation for Research of Rio de Janeiro (Faperj) and CNPq, respectively.

\section{References}

$>1$ Barker DJ: In utero programming of chronic $>13$ Hubschle T, et al: Leptin-induced nuclear disease. Clin Sci (Lond) 1998; 95:115-128.

$>2$ Langley-Evans SC, McMullen S: Developmental origins of adult disease. Med Princ Pract 2010;19:87-98.

-3 Armitage JA, et al: Developmental programming of the metabolic syndrome by maternal nutritional imbalance: how strong is the evidence from experimental models in mammals? J Physiol 2004;561(Pt 2):355-377.

$\checkmark 4$ Waterland RA, Jirtle RL: Early nutrition, epigenetic changes at transposons and imprinted genes, and enhanced susceptibility to adult chronic diseases. Nutrition 2004;20: 63-68.

5 Parente LB, Aguila MB, Mandarim-de-Lacerda CA: Deleterious effects of high-fat diet on perinatal and postweaning periods in adult rat offspring. Clin Nutr 2008;27:623634.

6 Gregorio BM, et al: Maternal high-fat intake predisposes nonalcoholic fatty liver disease in C57BL/6 offspring. Am J Obstet Gynecol 2010;203:495e1-8.

7 Guo F, Jen KL: High-fat feeding during pregnancy and lactation affects offspring metabolism in rats. Physiol Behav 1995;57:681686.

$>8$ Collins S, et al: Role of leptin in fat regulation. Nature 1996;380:677.

$>9$ Ferezou-Viala J, et al: Long-term consequences of maternal high-fat feeding on hypothalamic leptin sensitivity and diet-induced obesity in the offspring. Am J Physiol Regul Integr Comp Physiol 2007;293:R1056R1062.

10 Beck B, et al: Hypothalamic orexigenic peptides are overexpressed in young Long-Evans rats after early life exposure to fat-rich diets. Biochem Biophys Res Commun 2006;342: 452-458.

11 Bouret SG: Early life origins of obesity: role of hypothalamic programming. J Pediatr Gastroenterol Nutr 2009;48(suppl 1):S31S38.

12 Friedman JM, Halaas JL: Leptin and the regulation of body weight in mammals. Nature 1998;395:763-770. translocation of STAT3 immunoreactivity in hypothalamic nuclei involved in body weight regulation. J Neurosci 2001;21:2413-2324.

$\checkmark 14$ Gao Q, et al: Disruption of neural signal transducer and activator of transcription 3 causes obesity, diabetes, infertility, and thermal dysregulation. Proc Natl Acad Sci USA 2004;101:4661-4666.

15 Hofbauer KG: Molecular pathways to obesity. Int J Obes Relat Metab Disord 2002; 26(suppl 2):S18-S27.

16 Hamann A, Matthaei S: Regulation of energy balance by leptin. Exp Clin Endocrinol Diabetes 1996;104:293-300.

17 Fraulob JC, et al: A mouse model of metabolic syndrome: insulin resistance, fatty liver and non-alcoholic fatty pancreas disease (NAFPD) in C57BL/6 mice fed a high fat diet. J Clin Biochem Nutr 2010;46:212-223.

18 Reeves PG, Nielsen FH, Fahey GC, Jr: AIN93 purified diets for laboratory rodents: final report of the American Institute of Nutrition ad hoc writing committee on the reformulation of the AIN-76A rodent diet. J Nutr 1993; 123:1939-1951.

19 Matthews DR, et al: Homeostasis model assessment: insulin resistance and beta-cell function from fasting plasma glucose and insulin concentrations in man. Diabetologia 1985;28:412-419.

20 Mandarim-de-Lacerda CA: Stereological tools in biomedical research. An Acad Bras Cienc 2003;75:469-486.

21 Catta-Preta M, et al: Modulation of cytokines, resistin, and distribution of adipose tissue in C57BL/6 mice by different high-fat diets. Nutrition 2012;28:212-219.

22 Prieur X, et al: Leptin regulates peripheral lipid metabolism primarily through central effects on food intake. Endocrinology 2008; 149:5432-5439.

23 Harris RB, Bowen HM, Mitchell TD: Leptin resistance in mice is determined by gender and duration of exposure to high-fat diet. Physiol Behav 2003;78:543-555.

24 Morrison CD, et al: Increased hypothalamic protein tyrosine phosphatase $1 \mathrm{~B}$ contributes to leptin resistance with age. Endocrinology 2007;148:433-440.

25 Seo S, et al: Requirement of Bardet-Biedl syndrome proteins for leptin receptor signaling. Hum Mol Genet 2009;18:1323-1331.

26 Plagemann A: Perinatal programming and functional teratogenesis: impact on body weight regulation and obesity. Physiol Behav 2005;86:661-668.

27 Gluckman PD, Hanson MA: Developmental origins of disease paradigm: a mechanistic and evolutionary perspective. Pediatr Res 2004;56:311-317.

28 Taylor PD, et al: Impaired glucose homeostasis and mitochondrial abnormalities in offspring of rats fed a fat-rich diet in pregnancy. Am J Physiol Regul Integr Comp Physiol 2005;288:R134-R139.

29 Winzell MS, Ahren B: The high-fat diet-fed mouse: a model for studying mechanisms and treatment of impaired glucose tolerance and type 2 diabetes. Diabetes 2004;53(suppl 3):S215-S219.

30 Taylor SI, Accili D, Imai Y: Insulin resistance or insulin deficiency. Which is the primary cause of NIDDM? Diabetes 1994;43:735740 .

31 Cerf ME: High fat programming of beta-cell failure. Adv Exp Med Biol 2010;654:77-89.

32 Cerf ME, et al: Islet cell response in the neonatal rat after exposure to a high-fat diet during pregnancy. Am J Physiol Regul Integr Comp Physiol 2005;288: R1122-R1128.

33 Gniuli D, et al: Effects of high-fat diet exposure during fetal life on type 2 diabetes development in the progeny. J Lipid Res 2008; 49:1936-1945.

-34 Neuschwander-Tetri BA: Nonalcoholic steatohepatitis and the metabolic syndrome. Am J Med Sci 2005;330:326-335.

35 Gauthier MS, Favier R, Lavoie JM: Time course of the development of non-alcoholic hepatic steatosis in response to high-fat dietinduced obesity in rats. Br J Nutr 2006;95: 273-281.

36 Charney E, et al: Childhood antecedents of adult obesity. Do chubby infants become obese adults? N Engl J Med 1976;295:6-9. 
-37 Koteish A, Diehl AM: Animal models of steatosis. Semin Liver Dis 2001;21:89-104.

38 den Boer M, et al: Hepatic steatosis: a mediator of the metabolic syndrome. Lessons from animal models. Arterioscler Thromb Vasc Biol 2004;24:644-649.

-39 McCurdy CE, et al: Maternal high-fat diet triggers lipotoxicity in the fetal livers of nonhuman primates. J Clin Invest 2009;119:323335.

-40 Hartil K, et al: Maternal substrate utilization programs the development of the metabolic syndrome in male mice exposed to high fat in utero. Pediatr Res 2009;66:368-373.
41 Jones HN, et al: High-fat diet before and during pregnancy causes marked up-regulation of placental nutrient transport and fetal overgrowth in C57/BL6 mice. FASEB J 2009; 23:271-278.

42 Spiegelman BM, Flier JS: Obesity and the regulation of energy balance. Cell 2001;104: 531-543.

43 Conceicao EP, et al: Higher white adipocyte area and lower leptin production in adult rats overfed during lactation. Horm Metab Res 2011;43:513-516.
44 Frederich RC, et al: Leptin levels reflect body lipid content in mice: evidence for diet-induced resistance to leptin action. Nat Med 1995;1:1311-1314.

-45 Teegarden SL, Scott AN, Bale TL: Early life exposure to a high fat diet promotes longterm changes in dietary preferences and central reward signaling. Neuroscience 2009; 162:924-932.

46 Gupta A, et al: Hypothalamic alterations in fetuses of high fat diet-fed obese female rats. J Endocrinol 2009;200:293-300.

-47 Plum L, Schubert M, Bruning JC: The role of insulin receptor signaling in the brain. Trends Endocrinol Metab 2005;16:59-65. 